\section{Exclusion of Influences of ARMS2 Polymorphisms on the Central Visual Field in Retinitis Pigmentosa}

\author{
Hidetaka Masahara $^{\mathrm{a}, \mathrm{b}}$ Mitsuru Nakazawa $^{\mathrm{a}}$ Eiji Kawamura $^{\mathrm{a}}$ Shuichiro Eguchi ${ }^{\mathrm{b}}$ \\ ${ }^{a}$ Department of Ophthalmology, Hirosaki University Graduate School of Medicine, Hirosaki, and b Eguchi Eye \\ Hospital, Hakodate, Japan
}

(C) S. Karger AG, Basel

\section{PROOF Copy for personal use only}

ANY DISTRIBUTION OF THIS ARTICLE WITHOUT WRITTEN CONSENT FROM S. KARGER AG, BASEL IS A VIOLATION OF THE COPYRIGHT.

\section{Key Words}

A69S - ARMS2 gene - Mean deviation slope - Polymorphism · Retinitis pigmentosa $\cdot$ Visual field

\begin{abstract}
Purpose: To investigate the effects of polymorphisms of the age-related maculopathy susceptibility 2 (ARMS2) gene on the central visual field defects in retinitis pigmentosa (RP). Subjects and Methods: The visual field was evaluated using the 10-2 Swedish Interactive Threshold Algorithm Fast Program and mean deviation (MD) slope, and regression coefficients of average sensitivity of the central 4 points (Cent4) were compared between each genetic subgroup. Results: The MD slope (right/left) was as follows: GG, $-1.37 \pm 2.18$ / $-0.89 \pm 1.15 ; \mathrm{GT},-0.56 \pm 1.40 /-0.77 \pm 1.04 ; \mathrm{TT},-0.75 \pm 0.64 /$ $-0.38 \pm 0.92 \mathrm{~dB} /$ year. The Cent4 was as follows: $\mathrm{GG},-1.34$ $\pm 2.37 /-1.60 \pm 3.21 ; \mathrm{GT},-1.15 \pm 2.08 / 1.07 \pm 1.80 ; \mathrm{TT},-1.20$ $\pm 0.91 /-0.65 \pm 1.37 \mathrm{~dB} /$ year. No significant differences in the degree of progression were observed when comparing groups. Conclusions: These data suggest that polymorphisms of the ARMS2 do not modify the progression of the central field of vision in RP patients.
\end{abstract}

(c) 2013 S. Karger AG, Basel

\section{Introduction}

Retinitis pigmentosa (RP) is an inherited and progressive retinal disease that initially begins with night blindness and causes visual field constriction, eventually resulting in blindness. In typical cases, mottled retinal appearance associated with bone spicule-like pigmentary deposits, attenuation of retinal arterioles and pallor of the optic disk are observed in the ocular fundus.

Recent advances in molecular genetics have revealed the causal genes for RP. A point mutation in the rhodop$\sin (\mathrm{RHO})$ gene was first identified as a gene responsible for one form of autosomal dominant RP in 1990 [1], and since that time, more than 70 causal genes have been implicated for all inherent types of RP, including syndromic RP (RetNet: Cloned and/or mapped genes causing retinal diseases, http://www.sph.uth.tmc.edu/retnet/disease. htm).

Analysis of the relationship between genetic abnormalities in RP and their clinical manifestations is also progressing. Previously, it was suggested that the assorted clinical presentations of RP were due to diversity in the aforementioned genes. However, detailed observations of clinical features of the patient's genealogy indicate that individual variation is exhibited in disease progression

Mitsuru Nakazawa, MD, PhD

Department of Ophthalmology, Hirosaki University Graduate School of Medicine 5 Zaifu-cho

Hirosaki 036-8562 (Japan)

E-Mail mitsuru@cc.hirosaki-u.ac.jp 
and severity even among patients in the same families that presumably carry the same mutations in the same causal genes. Therefore, to explain this diversity in clinical features or genetic heterogeneity, investigators have hypothesized that there are other putative modifying factors that promote photoreceptor cell degeneration associated with the primary causal gene mutation. If this modifying factor could be identified, it might facilitate determination of prognosis at a relatively early stage of the disease, and treatment could potentially be promptly administered to prevent any increase in disease severity. Recently, Venturini et al. [2] reported that the CNOT3 gene is a modifier gene for phenotypic variability in $\mathrm{RP}$ associated with a mutation in the PRPF31 gene, and their findings may facilitate identification of other modifier factors.

Genome-wide association studies for multifactorial diseases conducted in recent years have gradually identified susceptibility genes for eye diseases, such as age-related macular degeneration (AMD) and glaucoma. For example, AMD strongly correlates with the complement factor $\mathrm{H}(\mathrm{CFH})$ [3] and age-related maculopathy susceptibility 2 (ARMS2) [4-8] genes. Recently, $C F H$ polymorphisms have been known to be associated with glomerulonephritis [9], atypical hemolytic uremic syndrome [10], Alzheimer disease [11], atherosclerosis [12], systemic lupus erythematosus [13], multifocal choroiditis [14] and posterior involvement of sarcoidosis [15] as well as AMD. These reports indicate that the $\mathrm{CFH}$ polymorphisms may also act as a disease-modifying factor. Although the precise localization of the protein product of the ARMS2 gene is still controversial, one possibility is that the ARMS2 protein may be present in the mitochondria of the inner segment of the photoreceptor [16]. Reports have previously implicated pathological changes in retinal pigment epithelium (RPE) and lamina choroidocapillaris as the cause of AMD; however, this finding indicated that the influence of photoreceptor mitochondria should also be considered for AMD. This is because mitochondria, in addition to producing glutathione and nicotinamide adenine dinucleotide phosphate that deoxidize free radicals generated by exposure to light, are organelles containing proapoptotic molecules such as caspases calpains, calcium ions, and apoptosis-inducing factor. Therefore, the putative vulnerability of mitochondria produced by the ARMS2 polymorphisms may directly or indirectly affect the survival of surrounding cells and tissues [17]. Fritsche et al. [16] reported that the AMD odds ratio for the ARMS2 A69S single-nucleotide polymorphism (SNP; rs10490924) was 2.9 in heterozygotes and
8.1 in homozygotes, with minor allele frequency observed in $19.3 \%$ of healthy volunteers. A report examining Japanese subjects [18] found that the AMD odds ratio for the A69S was 1.54 in heterozygotes and 5.16 in homozygotes, with minor allele frequency observed in $38.5 \%$ of healthy volunteers. Another report [19] found that the minor allele frequency in the general Japanese population was $32.6 \%$. This suggests that approximately $35 \%$ of the general Japanese population has latent vulnerability in the structure and/or function of photoreceptor mitochondria.

Based on the hypothesis that the ARMS2 protein is localized in the photoreceptor mitochondria, the ARMS2 A69S variant, which may be present in $35 \%$ of RP patients, is also a candidate for a modifying factor that promotes photoreceptor degeneration in RP. It is clinically and genetically important to identify disease modifier factors as well as disease-causing genes. Therefore, this study investigated whether polymorphisms of ARMS2, a susceptibility gene for AMD, are indeed responsible for the diverse clinical features of RP, such as variations in the progression of the central visual field defects.

\section{Subjects and Methods}

\section{Research Design}

This study was carried out in the Department of Ophthalmology, Hirosaki University Hospital and Hirosaki University Graduate School of Medicine. A total of $86 \mathrm{RP}$ patients with a follow-up time of more than 12 months in the Retina Clinic of the Department of Ophthalmology at the Hirosaki University Hospital were invited to undergo genotyping of ARMS2 A69S variants.

A clinical diagnosis of RP was determined based on the following criteria: (1) fundus examination showing typical arteriolar attenuation and bilateral mottled appearance of fundus color in at least midperipheral areas; (2) rod-predominant degeneration shown on electroretinography (ERG) and/or initial symptoms with disturbance of dark adaptation, and (3) constriction of visual field defects evaluated by either a Goldmann perimeter or Humphrey visual field analyzer (HVFA, Humphrey Instruments, San Leandro, Calif., USA).

Inclusion criteria were: residual central visual field better than $-35.0 \mathrm{~dB}$ as evaluated by the 10-2 program of the Swedish Interactive Threshold Algorithm (SITA) Fast Program for the HVFA; the visual field was periodically examined by the 10-2 SITA Fast Program for the HVFA every 6 months for at least 1 year; reliable results of the visual field examination, i.e. visual field data with fixation loss scores of $\leq 20 \%$ and false-negative error $\leq 33 \%$. Exclusion criteria were: intraocular surgery during the observation period of each patient; presence of cataracts or other media opacities that would disturb visual field examination; retinal degenerations secondary to inflammation, or the presence of ocular diseases other than RP.

The study protocol was approved by the Committee on Ethics of the Hirosaki University Graduate School of Medicine and was 
performed according to the Declaration of Helsinki. Written informed consent was obtained from all subjects before participation in the study.

\section{Genomic DNA Genotyping}

For the molecular genetic study, genomic DNA was extracted from peripheral blood leukocytes and purified with the QIAamp ${ }^{\circledR}$ DNA Mini kit (QIAGEN Sciences, Germantown, Md., USA), and the SNP rs 10490924 or p.Ala69Ser of the ARMS2 gene was amplified by polymerase chain reaction (PCR), directly sequenced and genotyped. The two primer sets for rs10490924 of ARMS2 were $5^{\prime \prime}$-TAC CAG GAC GAT GGT AAC- $3^{\prime \prime}$ and $5^{\prime \prime}$-GAG GAA GGC TGA ATT GCC TA- $3^{\prime \prime}$, and the sequencing primer was $5^{\prime \prime}$-TAC CAG GAC GAT GGT AAC- ${ }^{\prime \prime}$.The amplifications of the SNPs were performed at $60^{\circ} \mathrm{C}$ annealing temperature for 40 cycles. The PCR fragments were purified by a QIAquick ${ }^{\circledR}$ PCR Purification kit (QIAGEN Sciences) and were sequenced with the Big Dye ${ }^{\circledR}$ Terminator v1.1 Cycle Sequencing kit on an automated DNA sequencer (ABI PRISM ${ }^{\mathrm{TM}}$ 310, Applied Biosystems, Santa Clara, Calif., USA).

\section{Relationship between Genotype and Phenotype}

Subjects were divided into 3 groups on the basis of the ARMS2 genotype (GG, GT and TT); we initially examined whether there was any difference between genotype frequency in patients in this study and the Japanese patients in previous reports $[18,19]$ (analysis 1). Then, the basic clinical background of the participants including patient ages at the enrollment and initial symptoms or diagnosis, mean total observation periods, mean deviation (MD) values, and the visual sensitivity of the 4 central test points (Cent 4 ) in both eyes at the time of enrollment were compared between the groups (analysis 2). Next, two different methods were used to analyze the influences of the ARMS2 genotypes on the progression of the central visual field defect in RP. First, regression coefficient distributions were retrospectively calculated from time courses of the MD values of the 10-2 program (decibels per year, MD slope) during the total observation period for each group, with the groups then compared (analysis 3). Second, regression coefficient distributions were retrospectively calculated from the time courses of the average sensitivity of the central $2^{\circ}$ of the visual field that were determined by the (Cent 4 ) of the 10-2 program (decibels per year, $\Delta$ Cent 4 ), with the values then compared between the groups (analysis 4).

\section{Statistical Analysis}

The $\chi^{2}$ test was used to determine whether there was any difference between the ARMS2 genotype frequency in our study and previous reports (analysis 1). The Kruskal-Wallis test was used to investigate the degree of progression of visual field impairment because the data for the patients' background data, the MD slope and the $\Delta$ Cent 4 did not show normality in distribution throughout the three GG, GT and TT groups (3-group analysis, analyses 2, 3 and 4). Similarly, we specifically compared the data obtained from GG and TT groups by the Mann-Whitney $U$ test (2-group analysis, analyses 2, 3 and 4). Because GG is a nonrisk homozygote whereas TT is a risk homozygote for AMD, we speculated that a comparison between these two wings could provide a difference more easily than the 3-group analysis. All statistical analyses were conducted using Statcel 2 (OMS, Saitama, Japan). $\mathrm{p}<0.05$ was considered statistically significant.

ARMS2 Polymorphisms and the Central

Visual Field of Retinitis Pigmentosa
Table 1. Frequency of genotypes of the ARMS2 A69S variant (analysis 1)

\begin{tabular}{lccc}
\hline \multirow{2}{*}{ Study } & \multicolumn{3}{c}{ Genotypes of the ARMS2 A69S variant } \\
\cline { 2 - 4 } & GG & GT & TT \\
\hline Present study $(\mathrm{n}=60)$ & $20(33.3)$ & $35(58.3)$ & $5(8.3)$ \\
Fuse et al. [18] $(\mathrm{n}=138)$ & $64(46.4)$ & $58(42.0)$ & $16(11.6)$ \\
Hayashi et al. [19] $(\mathrm{n}=1,336)$ & $502(37.6)$ & $638(47.8)$ & $196(14.6)$
\end{tabular}

Numbers of subjects are shown, with frequency percentages in parentheses.

\section{Results}

\section{Genotype Frequency (Analysis 1)}

A total of 60 unrelated patients with RP were enrolled in this study, and genotypes in the ARMS2 variants were obtained from blood specimens. The ARMS2 genotype frequency in the subjects in the present study was as follows: GG, 20 cases (33.3\%); GT, 35 cases (58.3\%), and TT, 5 cases $(8.3 \%)$. The allele frequency of the minor allele $(\mathrm{T})$ was $37.5 \%$ in the present study group. No significant difference $(p=0.10)$ was observed between the genotype frequency in our study and those reported in previous studies involving healthy Japanese subjects, as summarized in table 1 .

\section{Patient Background (Analysis 2)}

Of the $86 \mathrm{RP}$ patients recruited, 60 (34 males and 26 females) were eligible and completed a sufficient followup and examinations for the study. Patient background information regarding phenotypes in terms of ages, observation periods, gender and the progression of visual field defects in the central $10^{\circ}$ and $2^{\circ}$ of the visual fields was obtained from medical records. Patient background characteristics and clinical courses are summarized in table 2. No significant differences in ages at enrollment, ages at initial symptoms or diagnosis, observation periods, initial MD values and initial Cent 4 values were observed comparing the groups (table 2). Patient family histories revealed that 10 cases were autosomal dominant, 4 were autosomal recessive, 1 was $\mathrm{X}$-linked recessive, and 45 were simplex cases.

\section{Calculation of Degree of Progression of Visual Field \\ Constriction Using MD Slope (Analysis 3)}

As shown in table 3, the MD slope (mean \pm standard deviation, median value, right eye/left eye) calculated with the HVFA SITA Fast 10-2 Program was as follows: GG, 
Table 2. Patient data (analysis 2)

\begin{tabular}{|c|c|c|c|c|c|}
\hline & \multicolumn{3}{|c|}{ Genotypes of the ARMS2 A69S variant } & \multicolumn{2}{|l|}{$\mathrm{p}$ value } \\
\hline & $\mathrm{GG}(\mathrm{n}=20)$ & GT $(\mathrm{n}=35)$ & $\mathrm{TT}(\mathrm{n}=5)$ & GG:GT:TT & GG:TT \\
\hline Age 1 , years & $55.35 \pm 13.22(52)$ & $52.06 \pm 13.91(50)$ & $46.29 \pm 15.18(43)$ & 0.350 & 0.174 \\
\hline Age 2 , years & $33.75 \pm 19.19(38)$ & $36.69 \pm 18.24(36)$ & $31.43 \pm 16.60(38)$ & 0.753 & 0.825 \\
\hline Observation, months & $58.59 \pm 30.63(60)$ & $55.82 \pm 30.13(48)$ & $39.60 \pm 30.77(18)$ & 0.578 & 0.306 \\
\hline Gender (M:F) & $11: 9$ & $20: 15$ & $3: 2$ & & \\
\hline Initial $\mathrm{MD} \mathrm{R}, \mathrm{dB}$ & $-17.15 \pm 7.49(-17.76)$ & $-17.69 \pm 9.39(-17.29)$ & $-20.68 \pm 8.90(-16.81)$ & 0.912 & 0.761 \\
\hline Initial MD L, dB & $-17.52 \pm 7.50(-16.80)$ & $-17.62 \pm 9.94(-15.90)$ & $-14.41 \pm 17.22(-14.18)$ & 0.796 & 0.561 \\
\hline Initial Cent $4 \mathrm{R}, \mathrm{dB}$ & $25.53 \pm 6.24(24.25)$ & $24.58 \pm 8.01(26.50)$ & $22.80 \pm 12.45(28.25)$ & 0.902 & 0.729 \\
\hline Initial Cent $4 \mathrm{~L}, \mathrm{~dB}$ & $24.07 \pm 6.86(25.00)$ & $23.72 \pm 8.53(25.25)$ & $23.00 \pm 10.66(25.75)$ & 0.963 & 0.862 \\
\hline
\end{tabular}

Results are means \pm standard deviation, with median values in parentheses. Age $1=$ Age at enrollment; age $2=$ age at initial symptom or diagnosis; $\mathrm{R}$ = right eye; L = left eye; GG:GT:TT = 3-group comparison by Kruskal-Wallis test; GG:TT = 2-group comparison (GG and TT) by Mann-Whitney test.

Table 3. Degree of progression of visual field using MD slope (analysis 3)

\begin{tabular}{|c|c|c|c|c|c|}
\hline & \multicolumn{3}{|c|}{ Genotypes of the ARMS2 A69S variant } & \multicolumn{2}{|l|}{$\mathrm{p}$ value } \\
\hline & $\mathrm{GG}(\mathrm{n}=20)$ & $\mathrm{GT}(\mathrm{n}=35)$ & $\mathrm{TT}(\mathrm{n}=5)$ & GG:GT:TT & GG:TT \\
\hline Right eye, dB/year & $-1.37 \pm 2.18(-0.80)$ & $-0.56 \pm 1.40(-0.42)$ & $-0.75 \pm 0.64(-0.75)$ & 0.22 & 0.63 \\
\hline Left eye, dB/year & $-0.89 \pm 1.15(-0.51)$ & $-0.77 \pm 1.04(-0.49)$ & $-0.38 \pm 0.92(-0.02)$ & 0.69 & 0.34 \\
\hline
\end{tabular}

Results are means \pm standard deviation, with median values in parentheses. GG:GT:TT = 3-group comparison by Kruskal-Wallis test; GG:TT = 2-group comparison (GG and TT) by Mann-Whitney test.

$-1.37 \pm 2.18($ median -0.80$) /-0.89 \pm 1.15(-0.51) \mathrm{dB} /$ year; GT, $-0.56 \pm 1.40(-0.42) /-0.77 \pm 1.04(-0.49) \mathrm{dB} /$ year, and TT, $-0.75 \pm 0.64(-0.75) /-0.38 \pm 0.92(-0.02) \mathrm{dB} /$ year. No significant differences in degree of progression were observed when comparing the groups (3-group comparisons by Kruskal-Wallis test: right eye, $\mathrm{p}=0.22$, and left eye, $\mathrm{p}=0.69 ; 2$-group comparisons by Mann-Whitney $\mathrm{U}$ test: right eye, $\mathrm{p}=0.63$, and left eye, $\mathrm{p}=0.34$, respectively).

\section{Calculation of Degree of Progression of the Mean}

Threshold Decrease in the Cent4 (Analysis 4)

As shown in table 4 , the degree of progression of the mean threshold decrease in the Cent 4 ( $\Delta$ Cent 4 , mean \pm standard deviation, right eye/left eye) with HVFA 10-2 was as follows: GG, $-1.34 \pm 2.37$ (median -1.11$) /-1.60 \pm$ $3.21(-1.00) \mathrm{dB} /$ year; GT, $-1.15 \pm 2.08(-0.79) /-1.07 \pm$ $1.80(-0.50) \mathrm{dB} /$ year, and TT, $-1.20 \pm 0.91(-1.20) /-0.65$ $\pm 1.37(-0.95) \mathrm{dB} /$ year. No significant differences in degree of progression were observed when comparing the groups (3-group comparisons by Kruskal-Wallis test: right eye, $\mathrm{p}=0.89$, and left eye, $\mathrm{p}=0.53 ; 2$-group comparisons by Mann-Whitney $U$ test: right eye, $p=0.68$, and left eye, $\mathrm{p}=1.00$, respectively).

\section{Discussion}

This is the first study to investigate the influences of the $A R M S 2$ polymorphisms on the visual function in RP. Patients were classified into one of three genotypes (GG, GT and TT) for the ARMS2 gene; this study showed that the ARMS2 polymorphisms did not correlate with the progression of the central visual field defect in RP. Although the distribution of the genetic background of the patients in each group was also largely heterogeneous, we thought that it was presumably evenly randomized by the ARMS2 polymorphisms, because the ARMS2 gene has not been known to be genetically and directly related to RP.

$\mathrm{RP}$ causes a progressive decrease in visual function, usually evaluated by visual acuity tests, ERG, or static and 
Table 4. Degree of progression of the mean threshold decrease in the Cent4 ( $\Delta$ Cent 4$)$

\begin{tabular}{|c|c|c|c|c|c|}
\hline & \multicolumn{3}{|c|}{ Genotypes of the ARMS2 A69S variant } & \multicolumn{2}{|l|}{$\mathrm{p}$ value } \\
\hline & $\mathrm{GG}(\mathrm{n}=20)$ & GT $(n=35)$ & $\mathrm{TT}(\mathrm{n}=5)$ & GG:GT:TT & GG:TT \\
\hline Right eye, dB/year & $-1.34 \pm 2.37(-1.11)$ & $-1.15 \pm 2.08(-0.79)$ & $-1.20 \pm 0.91(-1.20)$ & 0.89 & 0.68 \\
\hline Left eye, dB/year & $-1.60 \pm 3.21(-1.00)$ & $-1.07 \pm 1.80(-0.50)$ & $-0.65 \pm 1.37(-0.95)$ & 0.53 & 1.00 \\
\hline
\end{tabular}

Results are means \pm standard deviation, with median values in parentheses. GG:GT:TT = 3-group comparison by Kruskal-Wallis test; GG:TT = 2-group comparison (GG and TT) by Mann-Whitney test.

kinetic visual field testing. ERG, which can detect a decrease or loss in signal amplitude in the early disease stages, is useful for diagnosis but is not suitable for follow-up observations, because most patients with RP demonstrate extinguished amplitudes with clinically available equipment. Although many researchers have used isopters in kinetic perimetry to monitor the progression of RP [20], the results are not quantitative. There are other useful techniques for monitoring phenotypic features of RP, such as macular focal ERG [21], microperimetry [22] and optical coherent tomography [23]; however, automated perimetry using an HVFA is the simplest and least invasive technique. Because the vision of many RP patients is restricted to within $10^{\circ}$ by the time they present to an ophthalmologist, the HVFA 10-2 is better than the HVFA 30-2 for monitoring visual function [24]. Hirakawa et al. [25] conducted perimetry for more than 5 years using an HVFA 10-2 in patients with RP who had shown progression for 3.5 years or longer. They found that for approximately $50 \%$ of patients, MD values can undergo linear regression and can be used to measure the rate of visual progression [25]. In addition, Iijima [24] found that because the surrounding visual field sensitivity was approximately $0 \mathrm{~dB}$ in $\mathrm{RP}$ progression, the mean sensitivity of the Cent 4 was a more suitable measure than MD values for observing disease progression. Thus, the present study adopted MD slopes according to perimetry (measured using the HVFA 10-2 SITA Fast Program), and degree of progression of the Cent4 (measured using HVFA 10-2 SITA), for monitoring progression in the visual function of patients with RP. Because the Cent 4 reflects the visual sensitivity in the central $2^{\circ}$ of the visual field that consists of only cone photoreceptors, the Cent 4 can be considered as isolated cone function.

The genetic background for RP is largely heterogeneous. Genes involved in RP can be broadly classified into two types: (1) genes expressed specifically in photoreceptor cells or RPE, which when mutated primarily lead to

ARMS2 Polymorphisms and the Central

Visual Field of Retinitis Pigmentosa cell death in the photoreceptor cells and/or RPE, and (2) ubiquitously expressed genes, which when mutated cause degeneration specifically in photoreceptor cells due to lack of the protein. The former type includes the $R H O$ [1], peripherin/RDS (PRPH2) [26, 27] genes and the genes encoding $\alpha$ - and $\beta$-subunits of cGMP-phosphodiesterase (PDE6A, PDE6B) [28, 29], whereas the latter includes the RPGR [30], PRPF31 [31], PRPF3 [32], PRPF8 [33], IMPDH1 [34] and Mertk [35, 36] genes. These findings indicate that photoreceptors and RPE are much more active in protein synthesis than other tissues and that photoreceptors and RPE show high levels of gene expression and protein metabolism. Because mitochondria play a key role in protein synthesis by virtue of their role in energy production, mitochondrial dysfunction may influence photoreceptor survival and modify disease severity.

In recent years, genome-wide association studies for multifactorial diseases have been conducted and have identified susceptibility genes for AMD. For example, the CFH gene [3] in 2005 and, later, the ARMS2 gene were indicated as being involved in AMD onset [7]. Subsequently, several other reports $[4,5,8,16]$ have supported these results, and the ARMS2 is now widely recognized as another AMD susceptibility gene. The high-temperature requirement factor A1 (HTRA1) gene exists downstream of the ARMS2, and an SNP is present in the promoter region of the HTRA1, rs11200638 (G625A), known to correlate with AMD onset $[37,38]$. However, because this polymorphism and the A69S polymorphism in the ARMS2 often exist simultaneously, there is debate as to whether the ARMS2 gene or the HTRA1 gene is significantly related to AMD onset. It has also been reported that decreased ARMS2 protein expression is involved in AMD onset [16]. This decreased protein expression is considered to be due to unstable mRNA caused by a deletion-insertion polymorphism in the $3^{\prime}$-untranslated region between the stop codon that exists simultaneously with the A69S polymorphism and polyadenylic acid [16].

Ophthalmologica

DOI: $10.1159 / 000355093$ 
Meanwhile, the localization and actions of the ARMS2 gene product remain unclear. Kanda et al. [8] reported that the ARMS2 mRNA was detected in the human retina and various cell lines. These transcripts encode a $12-\mathrm{kDa}$ protein that localizes to the mitochondrial outer membrane when expressed in mammalian cells [8]. Fritsche et al. [16] showed that the ARMS2 protein in the human retina localized to the photoreceptor layer and that it demonstrates a minor dot-like staining in the ellipsoid region of the rod and cone inner segments, which colocalizes with a mitochondrial marker.

The minor allele frequency of the ARMS2 polymorphisms has been reported to be $35 \%$ in the Japanese population [18, 19], and the present study indicated a similar minor allele frequency in patients with RP. This signifies that a certain type of vulnerability exists in the mitochondria of approximately $35 \%$ of Japanese patients with RP. $\mathrm{RP}$ is a disease characterized by structural or functional stress in the photoreceptor cells due to specifically expressed genetic abnormalities occurring in photoreceptor cells or RPE cells. Apoptosis, the process of programmed cell death, occurs when this stress exceeds a certain threshold [39]. In RP, irrespective of the causal gene, it appears that degeneration is eventually caused by apoptosis [40]. Mitochondria play a key part in the regulation of apoptosis [40]. In general, when the process of apoptosis begins, mitochondria cease energy production and begin to release cytochrome c. This activates caspases through apoptotic protease-activating factor 1, ultimately leading to cell death. Apoptosis-inducing factor, also present in mitochondria, is involved in apoptosis signaling through its release into the cytoplasm, where it is transported into the nucleus, causing DNA fragmentation [40]. Thus, mitochondria appear to be directly or indirectly involved in RP pathology, and the ARMS2 polymorphisms may act as a modifying factor of RP severity. However, many questions regarding the localization and functions of the ARMS2 protein remain unanswered. Wang et al. [41] indicated that the ARMS2 protein was mainly distributed in the cytosol, rather than in the mitochondrial outer membrane, and that ARMS2 may not confer risk to onset of AMD through the mitochondrial pathway. Further, Xu et al. [42] reported that there was endogenous expression of the ARMS2 in a human RPE cell line and that the ARMS2 played a role in the phagocytic function of RPE cells. Further research is necessary to reconcile these discrepancies.

In conclusion, this was the first study to investigate the influences of the ARMS2 polymorphisms on visual function in RP. Because we did not perform mutation screening for our RP patients, we cannot discuss the relationship between causative genes for RP and the ARMS2 gene. Al-though it appears that polymorphisms of the $A R M S 2=$ (an AMD risk factor) do not impair the central field of vision in RP patients, further study with RP patients associated with the same causative gene mutation is necessary to minimize the confounding factor of genetic diversity.

\section{Acknowledgments}

We wish to thank Mr. Naoya Yamamoto and Miss Yukari Chiba for technical assistance. This study was supported by a Grantin-Aid for Scientific Research (C-24592616) from the Japan Society for the Promotion of Science (to M.N.).

\section{References}

1 Dryja TP, McGee TL, Reichel E, Hahn LB, Cowley GS, Yandell DW, Sandberg MA, Berson EL: A point mutation of the rhodopsin gene in one form of retinitis pigmentosa. $\mathrm{Na}$ ture 1990;343:364-366

2 Venturini G, Rose AM, Shah AZ, Bhattacharya SS, Rivolta C: Cnot3 is a modifier of PRPF31 mutations in retinitis pigmentosa with incomplete penetrance. PLoS Genet 2012;8:e1003040.

3 Klein RJ, Zeiss C, Chew EY, Tsai JY, Sackler RS, Haynes C, Henning AK, SanGiovanni JP, Mane SM, Mayne ST, Bracken MB, Ferris FL, Ott J, Barnstable C, Hoh J: Complement factor $\mathrm{H}$ polymorphism in age-related macular degeneration. Science 2005;308:385-389.

4 Rivera A, Fisher SA, Fritsche LG, Keilhauer CN, Lichtner P, Meitinger T, Weber BH: Hypothetical LOC387715 is a second major susceptibility gene for age-related macular degeneration, contributing independently of complement factor $\mathrm{H}$ to disease risk. Hum Mol Genet 2005;14:3227-3236.

5 Conley YP, Jakobsdottir J, Mah T, Weeks DE, Klein R, Kuller L, Ferrell RE, Gorin MB: CFH, ELOVL4, PLEKHA1 and LOC387715 genes and susceptibility to age-related maculopathy: AREDS and CHS cohorts and meta-analyses. Hum Mol Genet 2006;15:3206-3218.

6 Schmidt S, Hauser MA, Scott WK, Postel EA, Agarwal A, Gallins P, Wong F, Chen YS, Spencer K, Schnetz-Boutaud N, Haines JL, PericakVance MA: Cigarette smoking strongly modifies the association of LOC387715 and age-related macular degeneration. Am J Hum Genet 2006;78:852-864.

7 Seddon JM, Francis PJ, George S, Schultz DW, Rosner B, Klein ML: Association of CFH
Y402H and LOC387715 A69S with progression of age-related macular degeneration JAMA 2007;297:1793-1800.

8 Kanda A, Chen W, Othman M, Branham KE, Brooks M, Khanna R, He S, Lyons R, Abecasis GR, Swaroop A: A variant of mitochondrial protein LOC387715/ARMS2, not HTRA1, is strongly associated with age-related macular degeneration. Proc Natl Acad Sci USA 2007; 104:16227-16232.

9 Abrera-Abeleda MA, Nishimura C, Smith JL, Sethi S, McRae JL, Murphy BF, Silvestri G, Skerka C, Józsi M, Zipfel PF, Hageman GS, Smith RJ: Variations in the complement regulatory genes factor $\mathrm{H}(\mathrm{CFH})$ and factor $\mathrm{H}$ related 5 (CFHR5) are associated with membranoproliferative glomerulonephritis type II (dense deposit disease). J Med Genet 2006;43: 582-589. 
10 Heinen S, Jozsi M, Hartmann A, Noris M, Remuzzi G, Skerka C, Zipfel PF: Hemolytic uremic syndrome: a factor $\mathrm{H}$ mutation (E1172S top) causes defective complement control at the surface of endothelial cells. J Am Soc Nephrol 2007; 18:506-514.

11 Zetterberg M, Landgren S, Andersson ME, Palmér MS, Gustafson DR, Skoog I, Minthon L, Thelle DS, Wallin A, Bogdanovic N, Andreasen N, Blennow K, Zetterberg H: Association of complement factor $\mathrm{H}$ Y $402 \mathrm{H}$ gene polymorphism with Alzheimer's disease. Am J Med Genet B Neuropsychiatr Genet 2008; 147B:720-726.

12 Oksjoki R, Jarva H, Kovanen PT, Laine P, Meri S, Pentikainen MO: Association between complement factor $\mathrm{H}$ and proteoglycans in early human coronary atherosclerotic lesions: implications for local regulation of complement activation. Arterioscler Thromb Vasc Biol 2003;23:630-636.

13 Jonsen A, Nilsson SC, Ahlqvist E, Svenungsson E, Gunnarsson I, Eriksson KG, Bengtsson A, Zickert A, Eloranta ML, Truedsson L, Rönnblom L, Nordmark G, Sturfelt G, Blom AM: Mutations in genes encoding complement in hibitors $\mathrm{CD} 46$ and $\mathrm{CFH}$ affect the age at nephritis onset in patients with systemic lupus erythematosus. Arthritis Res Ther 2011;13:R206.

14 Ferrara DC, Merriam JE, Freund KB, Spaide RF, Takahashi BS, Zhitomirsky I, Fine HF, Yannuzzi LA, Allikmets R: Analysis of major alleles associated with age-related macular degeneration in patients with multifocal choroiditis: strong association with complement factor H. Arch Ophthalmol 2008;126:1562-1566.

15 Thompson IA, Liu B, Sen HN, Jiao X, Katamay R, Li Z, Hu M, Hejtmancik F, Nussenblatt RB. Association of complement factor $\mathrm{H}$ tyrosine 402 histidine genotype with posterior involvement in sarcoid-related uveitis. Am J Ophthalmol 2013;155:1068-1074.

16 Fritsche LG, Loenhardt T, Janssen A, Fisher SA, Rivera A, Keilhauer CN, Weber BH: Agerelated macular degeneration is associated with an unstable ARMS2 (LOC387715) mRNA. Nat Genet 2008;40:892-896.

17 Nakazawa M: Effects of calcium ion, calpains, and calcium channel blockers on retinitis pigmentosa. J Ophthalmol 2011;2011:292040.

18 Fuse N, Mengkegale M, Miyazawa A, Abe T, Nakazawa T, Wakusawa R, Nishida K: Polymorphisms in ARMS2 (LOC387715) and LOXL1 genes in the Japanese with age-related macular degeneration. Am J Ophthalmol 2011;151:550-556.

19 Hayashi H, Yamashiro K, Gotoh N, Nakanishi H, Nakata I, Tsujikawa A, Otani A, Saito M, Iida T, Matsuo K, Tajima K, Yamada R, Yoshimura N: $\mathrm{CFH}$ and ARMS2 variations in age-related macular degeneration, polypoidal choroidal vasculopathy, and retinal angiomatous proliferation. Invest Ophthalmol Vis Sci 2010;51:5914-5919.

20 Grover S, Fishman GA, Anderson RJ, Alexander KR, Derlacki DJ: Rate of visual field loss in retinitis pigmentosa. Ophthalmology 1997; 104:460-465.
21 Terasaki H, Miyaki Y, Nomura R, Piao CH, Hori K, Niwa T, Kondo M: Focal macular ERGs in eyes after removal of macular ILM during macular hole surgery. Invest Ophthalmol Vis Sci 2001;42:229-234.

22 Radtke ND, Aramant RB, Petry HM, Green PT, Pidwell DJ, Seiler MJ: Vision improvement in retinal degeneration patients by implantation of retina together with retinal pigment epithelium. Am J Ophthalmol 2008;146: 172-182.

23 Oishi A, Nakamura H, Tatsumi I, Sasahara M, Kojima H, Kurimoto M, Otani A, Yoshimura N: Optical coherence tomographic pattern and focal electroretinogram in patients with retinitis pigmentosa. Eye 2009;23: 299-303.

24 Iijima H: Correlation between visual sensitivity loss and years affected for eyes with retinitis pigmentosa. Jpn J Ophthalmol 2012;56: 224-229.

25 Hirakawa H, Iijima H, Gohdo T, Imai M, Tsukahara S: Progression of defects in the central 10-degree visual field of patients with retinitis pigmentosa and choroideremia. Am J Ophthalmol 1999;127:436-442.

26 Farrar GJ, Kenna P, Jordan SA, KumarSingh R, Humphries MM, Sharp EM, Sheils DM, Humphries P: A three-base-pair deletion in the peripherin-RDS gene in one form of retinitis pigmentosa. Nature 1991;354: 478-480.

27 Kajiwara K, Hahn LB, Mukai S, Travis GH, Berson EL, Dryja TP: Mutations in the human retinal degeneration slow gene in autosomal dominant retinitis pigmentosa. Nature 1991; 354:480-483.

28 Dryja TP, Rucinski DE, Chen SH, Berson EL: Frequency of mutations in the gene encoding the alpha subunit of rod cGMP-phosphodiesterase in autosomal recessive retinitis pigmentosa. Invest Ophthalmol Vis Sci 1999;40: 1859-1865.

29 McLaughlin ME, Sandberg M, Berson E, Dryja TP: Recessive mutations in the gene encoding the beta-subunit of rod phosphodiesterase in patients with retinitis pigmentosa. Nat Genet 1993;4:130-134

30 Meindl A, Dry K, Herrmann K, Manson F, Ciccodicola A, Edgar A, Carvalho MR, Achatz $\mathrm{H}$, Hellebrand $\mathrm{H}$, Lennon A, Migliaccio C, Porter K, Zrenner E, Bird A, Jay M, Lorenz B, Wittwer B, D'Urso M, Meitinger T, Wright A: A gene (RPGR) with homology to the RCC1 guanine nucleotide exchange factor is mutated in X-linked retinitis pigmentosa (RP3). Nat Genet 1996;13:35-42.

31 Vithana EN, Abu-Safieh L, Allen MJ, Carey A, Papaioannou M, Chakarova C, Al-Maghtheh M, Ebenezer ND, Willis C, Moore AT, Bird AC, Hunt DM, Bhattacharya SS: A human homolog of yeast pre-mRNA splicing gene, PRP31, underlies autosomal dominant retinitis pigmentosa on chromosome 19q13.4 (RP11). Mol Cell 2001;8:375-381.

32 Chakarova CF, Hims MM, Bolz H, AbuSafieh L, Patel RJ, Papaioannou MG, Inglehearn CF, Keen TJ, Willis C, Moore AT,
Rosenberg T, Webster AR, Bird AC, Gal A, Hunt D, Vithana EN, Bhattacharya SS: Mutations in HPRP3, a third member of premRNA splicing factor genes, implicated in autosomal dominant retinitis pigmentosa. Hum Mol Genet 2002;11:87-92.

33 McKie AB, McHale JC, Keen TJ, Tarttelin EE, Goliath R, van Lith-Verhoeven JJC, Greenberg J, Ramesar RS, Hoyng CB, Cremers FRM, Mackey DA, Bhattacharya SS, Bird AC, Markham AF: Mutations in the pre-mRNA splicing factor gene PRPC8 in autosomal dominant retinitis pigmentosa (RP13). Hum Mol Genet 2001;10:1555-1562.

34 Bowne SJ, Sullivan LS, Blanton SH, Cepko CL, Blackshaw S, Birch DG, Hughbanks-Wheaton D, Heckenlively JR, Daiger SP: Mutations in the inosine monophosphate dehydrogenase 1 gene (IMPDH1) cause the RP10 form of autosomal dominant retinitis pigmentosa. Hum Mol Genet 2002;11:559-568.

35 D'Cruz PM, Yasumura D, Weir J, Matthes MT, Abderrahim H, LaVail MM, Vollrath D: Mutation of the receptor tyrosine kinase gene Mertk in the retinal dystrophic RCS rat. Hum Mol Genet 2000;9:645-651.

36 Gal A, Li Y, Thompson DA, Weir J, Orth U, Jacobson SG, Apfelstedt-Sylla E, Vollrath D: Mutations in MERTK, the human orthologue of the RCS rat retinal dystrophy gene, cause retinitis pigmentosa. Nat Genet 2000;26:270271.

37 Cameron DJ, Yang Z, Gibbs D, Chen H, Kaminoh Y, Jorgensen A, Zeng J, Luo L, Brinton E, Brinton G, Brand JM, Bernstein PS, Zabriskie NA, Tang S, Constantine R, Tong Z, Zhang K: HTRA1 variant confers similar risks to geographic atrophy and neovascular agerelated macular degeneration. Cell Cycle 2007;6:1122-1125.

38 Dewan A, Liu M, Hartman S, Zhang SS, Liu DT, Zhao C, Tam PO, Chan WM, Lam DS, Snyder M, Barnstable C, Pang CP, Hoh J: HTRA1 promoter polymorphism in wet agerelated macular degeneration. Science 2006; 314:989-992.

39 Chang GQ, Hao Y, Wong F: Apoptosis: final common pathway of photoreceptor death in rd, rds, and rhodopsin mutant mice. Neuron 1993; 11:595-605.

40 Susin SA, Lorenzo HK, Zamzami N, Marzo I, Snow BE, Brothers GM, Mangion J, Jacotot E, Costantini P, Loeffler M, Larochette N, Goodlett DR, Aebersold R, Siderovski DP, Penninger JM, Kroemer G: Molecular characterization of mitochondrial apoptosis-inducing factor. Nature 1999;397:441-446.

41 Wang G, Spencer KL, Court BL, Olson LM, Scott WK, Haines JL, Pericak-Vance MA: Localization of age-related macular degeneration-associated ARMS2 in cytosol, not mitochondria. Invest Ophthalmol Vis Sci 2009;50: 3084-3090.

42 Xu YT, Wang Y, Chen P, Xu HF: Age-related maculopathy susceptibility 2 participates in the phagocytosis functions of the retinal pigment epithelium. Int J Ophthalmol 2012;5: 125-132.
ARMS2 Polymorphisms and the Central Visual Field of Retinitis Pigmentosa
Ophthalmologica

DOI: $10.1159 / 000355093$ 